\title{
Que viajar é este? Descoberta e reflexão em Viagem a Portugal, de José Saramago
}

\author{
Shirley Aparecida Gomide Cabral ${ }^{1}$
}

RESUMO: Objetiva-se com este trabalho analisar o texto de José Saramago como exemplo atual de narrativa de viagem, a partir de propostas como o enfretamento entre a memória e o esquecimento; a crítica ao comportamento do povo português frente à sua própria cultura; e a influência da história a partir da perspectiva de Walter Benjamin para a identificação de Portugal por meio de uma mirada microscópica sobre este país.

ABSTRACT: The aim of this work is to analyze José Saramago's text as a contemporary example of a travel narrative, from proposals such as the contrast between the memory and the forgetting; the critic to Portuguese behavior in face of their own culture; and the influence of history by Walter Benjamin's perspective to identify Portugal through a microscopic look.

PALAVRAS-CHAVE: Narrativa de viagem; Identidade; Memória KEYWORDS: Travel narrative; Identity; Memory

Eis a boa filosofia: tudo é viagem. É viagem o que está à vista e o que se esconde, é viagem o que se toca e o que se adivinha, é viagem o estrondo das águas caindo e esta subtil dormência que envolve os montes.

(José Saramago)

1 Mestranda em Estudos Literários pela Universidade Federal de Minas Gerais; Biblioteca e Arquivo: a Bíblia no conto de Moacyr Scliar 
Conhecer, descobrir, inventar. Conceitos que se entrelaçam quando se pensa em empreender alguma viagem, quer seja uma viagem propriamente dita ou ainda uma viagem literária. A chamada literatura de viagens, subgênero da alta literatura, como propõe Fernando Cristóvão (2002) em seu texto, parte de todos estes conceitos e dá as mãos, ainda, à História, à Antropologia e à própria Literatura. A viagem como conhecimento, proposta fundamental das narrativas que desde o século XV se encaixam nessa tipologia, atravessou a história e chegou até hoje em formas diversas de narrar, que tem no descobrimento, na novidade, na aventura e na construção de novos mundos seu leitmotiv. Esse cruzamento entre as várias ciências, abordado desde as primeiras narrativas de viajantes religiosos como Fernão Cardim e André de Thevet, passando por naturalistas como Spix e Martius, também se faz presente em autores mais atuais, como José Saramago e sua Viagem a Portugal, texto que servirá de base para o estudo aqui proposto.

Não se considera tal texto como uma narrativa que enfoca uma viagem romântica, tampouco exploratória; nele, os elementos principais são a valorização e a construção da identidade e da história de um povo por ele mesmo. Apartando-se da estrutura narrativa de outros mais conhecidos relatos de viagem, em que o narrador viajante sai de seu próprio país em busca de um novo mundo e de novas experiências, Saramago demonstra que esse novo mundo, não tão novo assim, está mais perto do que se imagina; é seu próprio país, que sempre esteve presente, em suas tradições, em seus monumentos, em suas histórias e em sua cultura - elementos que parecem transitar à margem da vida de Portugal.

Viagem a Portugal demonstra que há um país a ser (re)descoberto, e fazendo justamente a aproximação dessa perspectiva à narrativa dos naturalistas, através de alguns pontos de contato entre suas formas discursivas, resguardando suas diferenças, é que o presente artigo se propõe a analisar o texto de Saramago como um exemplo atual de narrativa de viagem, a partir de propostas como o enfrentamento entre 
a memória e o esquecimento, levantando questionamentos que entram em consonância com o pensamento de Hugo Achugar em Planetas sem boca; a crítica ao comportamento do povo português frente à sua própria cultura; e a influência da história a partir da perspectiva de Walter Benjamin, em suas teses sobre o conceito de História, para a identificação de Portugal através de uma mirada microscópica sobre este país. A viagem é o fio que conduz o leitor, que também se faz viajante juntamente com o narrador, pelo trajeto histórico que Saramago traça ao percorrer cada pequena cidade, ao entrar em cada igreja e ao passar em frente a cada casa que traz à memória a vida e a obra de grandes personagens da literatura portuguesa, como Camilo Castelo Branco, Eça de Queirós, Teixeira de Pascoaes e José Régio, dialogando ainda com outras narrativas e próceres, como Viagens na minha terra, de Almeida Garrett - da qual parece ser filho legítimo - e Camões.

Para considerar Viagem a Portugal uma narrativa de viagem, parte-se dos conceitos tanto teóricos quanto de outros relatos que percorrem aproximadamente o mesmo trajeto do narrador: textos que consideram o novo, o desconhecido, como uma nova realidade a ser apreendida, mostrada, registrada e admirada. Seguindo a esteira de tal sistema narrativo, Saramago apresenta ao leitor seu "guia de viagem" de uma maneira um pouco diversa, ao trazer esses novos elementos a partir de uma perspectiva histórica e até mesmo um pouco testemunhal, ao aliar as descrições que faz ao contexto histórico de cada monumento, de cada um dos personagens que compõem a história de seu país - um país que, dentro da narrativa, se descobre, se registra, adquirindo novas imagens e nova identidade.

Apesar de separados por vários séculos e múltiplos acontecimentos, Viagem a Portugal dialoga com as demais narrativas de viagem em vários aspectos. Pode-se citar, em primeiro lugar, a própria ideia de sua escrita. Assim como os relatos dos viajantes dos séculos XV e XVI, principalmente, o texto de Saramago também surge a partir de uma demanda direcionada. Os livros de viajantes que Fernando 
Cristóvão afirma terem sido corrigidos e manipulados "para saciarem um público ávido de novidades, aventuras e emoções fortes, sobretudo à volta de épicas descobertas e conquistas" (CRISTOVÃO, 2002, p. 25) são, de certa forma, precursores da ideia que fez com que o Círculo de Leitores solicitasse a Saramago que escrevesse um guia turístico sobre Portugal; este não hesitou em sugerir que tal empreitada fosse adaptada a uma narrativa de viagem, e, a partir disso, realizou todo um projeto literário e crítico que, utilizando a viagem como motivo principal, traz à tona várias discussões sobre a memória, a cultura e a identidade de Portugal, como se verá posteriormente.

Ainda na mesma linha de pensamento, assim como as edições posteriores aos descobrimentos se fizeram valer do uso de imagens "a fim de melhor agradarem aos leitores, acompanhadas de muitas ilustrações, gravuras, desenhos e mapas." (CRISTOVÃO, p. 26), também o texto de Saramago, em algumas edições, traz mapas e fotografias, conduzindo o leitor pelo trajeto da viagem empreendida por seu narrador. ${ }^{2}$

A literatura de viagens carrega em si componentes etnográficos e antropológicos, históricos e geográficos, e é a partir de tais características que se considera interessante verificar, em Viagem a Portugal, um momento em que o narrador tenta se colocar um pouco alheio a essa tradição:

O viajante não veio fazer trabalho de etnólogo ou de sociólogo, dele ninguém esperará supremas descobertas nem sequer outras menores: tem apenas o legítimo e humaníssimo desejo de ver o que outras pessoas viram, de assentar os pés onde outros pés deixaram marcas. (SARAMAGO, 2007, p.33)

Do mesmo modo, Claude Lévi-Strauss, em Tristes trópicos, logo no primeiro capítulo faz questão de deixar claro que não está

2 A edição utilizada como referência para este trabalho, da editora Companhia das Letras, não contempla os mapas e ilustrações que mencionamos acima. 
escrevendo uma narrativa de viagem. Entretanto, ao longo dos dois textos, fica claro que a premissa inicial defendida tanto por ele quanto pelo narrador de Viagem a Portugal é falsa. Os relatos descritivos que ambos fazem dos costumes, das paisagens, quer estejam impregnados de adjetivos ou carentes deles, trazem à memória do leitor os relatos de Caminha sobre o Novo Mundo, o encontro de Jean de Lery e Fernão Cardim com povos e culturas tão diferentes, a grandiosa novidade que se desvela ante os olhos de Humboldt, que descreve a natureza de uma forma extremamente poética, quase como se pintasse um quadro; da mesma forma, Saramago poetiza ao entrelaçar vários elementos como visão, sons e sentimentos:

Claro que o viajante vai procurando, por metáfora, dizer o que sente. Mas quando do alto da estrada se vê este imenso mar e ao fundo dos rochedos a franja branca que inaudivel bate, quando apesar da distância a transparência das águas deixa ver as areias e as limosas pedras, o viajante pensa que só a grande música poderá exprimir o que os olhos se limitam a ver. Ou nem mesmo a música. Provavelmente o silêncio, nenhum som, nenhuma palavra, e também nenhuma pintura; apenas, afinal, o louvor do olhar: a vós, olhos, louvo e agradeço. (SARAMAGO, p.379)

A forma poética de falar sobre as ondas, "a franja branca que inaudivel bate", faz com que o uso de metáforas enriqueça o narrar do viajante e enalteça a grandiosidade de sua terra. Ao mesmo tempo em que afirma que busca as metáforas para expressar o que vê e sente, demonstra que tais imagens só podem ser apreendidas pela experiência, pelo olhar - "a vós, olhos, louvo e agradeço".

Esse olhar, em Viagem a Portugal, é paradoxal; ao mesmo tempo em que é estrangeiro em sua própria terra, é também um olhar nativo que busca reconhecer seus valores e sua história nos pequenos detalhes de sua viagem, construindo, assim, sua memória. Essa mirada interior que o narrador lança sobre Portugal oferece ao leitor uma nova perspectiva em termos de viagem: Portugal dos guias de viagem é completamente diferente daquele que se desvela a partir da escrita de Saramago. É um país com outras nuances, com particularidades que 
apenas o olhar minucioso e desprovido de preconceitos e estereótipos que o nativo traz pode desvelar ao leitor.

O processo da escrita é o mesmo em todos os relatos: o viajante escreve ao mesmo tempo em que viaja, relata ao mesmo tempo em que descobre, ainda que a obra final seja re-elaborada após o retorno à terra natal; a viagem e o fazer literário ocupam o mesmo espaço no percurso do viajante. Entretanto, como se pode notar, os antigos textos dos viajantes europeus possuem uma carga de novidade muito mais acentuada que o texto de Saramago, uma vez que o autor português já possui todo um background histórico que, junto ao percurso imposto ao seu narrador, tenta mostrar ao leitor-viajante. Para os viajantes dos séculos anteriores, não havia quase nenhum conhecimento prévio da realidade que estariam prestes a encontrar, salvo, em alguns casos, algumas leituras de outros relatos de viagens que chegavam a mencionar em determinadas passagens, ou, ainda, de algumas características do próprio estilo discursivo dos autores lidos que se faziam presentes nos textos desses viajantes.

De certa forma, Portugal também se faz desconhecido aos olhos do viajante, que por várias vezes "sente-se um tanto alheado, como se estivesse vendo e palpando testemunhos duma civilização e duma cultura totalmente estranha." (SARAMAGO, p. 158) Percebe-se, aqui, que o narrador de Viagem a Portugal se refere ao seu próprio país a partir de uma mirada estrangeira, como se sua própria história e sua própria cultura fossem testemunhos de uma memória que não lhe pertencesse.

Desse modo, além de resgatar a memória de seu país, Viagem a Portugal funciona como um testemunho, escrito nas paredes dos monumentos e casas visitadas pelo viajante. Para Hugo Achugar,

O fantasma de um Alzheimer coletivo percorre o presente fim de século. Todos estão/estamos ou parecem/parecemos estar atemorizados por uma perda de memória. Todos estão, estamos, parecem, parecemos estar angustiados pela imposição do esquecimento. Ou, se não é o mesmo, é parecido. Todos parecem estar, estamos ou estão, preocupados por democratizar o 
passado, descentralizar a história ou descolonizar a memória. (...) Por isso, penso que no monumento está a chave. No monumento e naquilo que vem atrás daqueles que construíram o monumento. No monumento como signo, que tenta vincular passado e futuro está a chave. No monumento, ou na lápide, que se supõe avisará aos que vem depois o que foi que aconteceu antes. No monumento como objetivação da memória. (ACHUGAR, 2006, p.168)

O monumento é o signo testemunhal da história; nele estão registrados fatos históricos, personagens que fizeram parte da escrita da memória de um povo, de uma cidade, de um país. Memória e história constituem a identidade de um povo, e, em Viagem a Portugal, memória e história são meras lembranças esfumaçadas pelo tempo. As ruínas, o desconhecimento da própria história e da própria cultura, o desleixo dos portugueses para com seus monumentos, revelam, em um nivel mais profundo, o descaso em relação a seu próprio passado. O viajante de Saramago critica essa atitude de esquecimento frente à sua história em vários momentos de seu percurso; citam-se aqui alguns deles que refletem bem essa visão:

Lá está a aguazinha clara e fresca, e agora o sol que mal se sente no rosto, mas faz festas nas mãos, e o viajante vai andando, vê que ainda está longe da povoação, hesita, porém há ali dois jovens, rapaz e rapariga, a apostar que são namorados. Estão sentados num muro derrubado, e pararam de conversar. $\mathrm{O}$ viajante chega-se a eles e pergunta: "Sabem dizer-me onde fica, aqui, a Capela da Nossa Senhora do Amparo?” O rapaz e a rapariga olham um para o outro, e é ele quem responde: "Capela de Nossa Senhora do Amparo? Não conheço. Se é a igreja que procura, fica lá em baixo, no povo." O viajante sabe muito bem o que quer, mas perturba-o a informação: "Não é isso, é a Capela da Nossa Senhora do Amparo de que falou o senhor Aquilino Ribeiro no livro", e, tendo dito isto, esperava ver abrirem-se os sorrisos dos namorados. Penas perdidas. Responde a rapariga, com modos de irritada por lhe ter sido cortado o galanteio: "Não senhor, não conhecemos." (SARAMAGO, p. 95-96)

Os jovens desconhecem a Capela sobre a qual o viajante pergunta; mais ofensiva ainda para o narrador, que em um intento de clarear-lhes a memória apela para a literatura, é a ignorância da rapariga. Perde-se o símbolo representado pelo monumento mencionado 
pelo viajante, e com ele toda sua carga histórica, ao substituí-lo por uma simples construção religiosa - a igreja. Em outra passagem, a crítica se faz diretamente ao estado de conservação dos monumentos, extensiva à conservação da memória cultural:

Seria estimável a vizinhança se não fosse encher o rio e entrar na igreja. O viajante não sabe como as coisas lá dentro se passam em momentos tais, se têm os santos de levantar os mantos para não se molharem, mas uma outra coisa sabe, é que está escrevendo estas palavras, que parecem falta de respeito, para disfarçar a indignação que sente por ver que assim ao respeito se falta a preciosas obras de arte, condenadas à morte pela indiferença e pelo desmazelo. O viajante deve confessá-lo aqui, não precisa de imagens sacras para orar aos pés delas, mas precisa de que elas sejam defendidas porque são obra do génio do homem, beleza criada. (SARAMAGO, p.160-161)

Além dos monumentos, paisagens naturais também são elementos de preocupação do narrador. Ao descrevê-las detalhadamente, mas não tão laudatoriamente como o fizeram os viajantes naturalistas, Saramago demonstra outra característica de sua escrita: um olhar microscópico sobre sua terra. A mirada, além de interior (pois se difere das outras narrativas de viagem por tratar de seu próprio país, aproximando-se, deste modo, de Viagens na minha terra de Almeida Garret, como já foi mencionado anteriormente), se debruça sobre pequenos detalhes do dia a dia português, como a comida, os costumes e as pessoas que constroem Portugal sem que sejam sequer mencionadas nas páginas da história.

Ao verificar tal escolha estética, percebe-se que paralelamente a ela corre ainda outro elemento que também se manifesta na viagem do narrador de Saramago - a história contada do ponto de vista dos vencidos, de seus personagens menores (o povo). A imagem de Lisboa que José Saramago oferece ao leitor é bastante critica, concentrada, como já foi dito, nos seres e nas coisas relegados pela história oficial lusitana. A chegada do narrador saramaguiano à capital e a longa explicação de quais seriam seus interesses como viajante nessa cidade já dão bem uma mostra disso: 
Cá está a coleira. O viajante disse e cumpriu: mal entrasse em Lisboa iria ao Museu de Arqueologia e Etnologia à procura da falada coleira usada pelo escravo dos Lafetás. Podem-se ler os dizeres: "esse preto he de Agostinho de Lafetá do Carvalhal de Óbidos." O viajante repete uma vez e outra para que fique gravado nas memórias esquecidas. Este objecto, se é preciso darlhe um preço, vale milhões e milhões de contos, tanto como os Jerónimos aqui ao lado, a Torre de Belém, o palácio do presidente, os coches por junto e atacado, provavelmente toda a cidade de Lisboa. Esta coleira é mesmo uma coleira, repare-se bem, andou no pescoço dum homem, chupou-lhe o suor, e talvez algum sangue, de chibata que devia ir ao lombo e errou o caminho. Agradece o viajante muito do seu coração quem recolheu e não destruiu a prova de um grande crime. (SARAMAGO, p. 355)

Procurar uma coleira. Eis o objetivo inicial da estada do viajante de Viagem a Portugal já ao entrar na capital de seu país. O objeto de sua atenção não poderia ser mais significativo: como ele mesmo ressalta, a coleira é, ao mesmo tempo, um objeto histórico marcado pela experiência viva dos homens, pois ela "andou no pescoço dum homem, chupou-lhe o suor, e talvez algum sangue" (SARAMAGO, p. 355); além disso, a coleira é também "a prova de um grande crime" (SARAMAGO, p. 355). Essa assertiva, contundente e direta, já revela, por si mesma, a parcialidade e a visão crítica do passado assumida pelo narrador. Ao invés de apresentar um objeto do passado de modo frio e supostamente isento, o viajante prefere ver na história as marcas das vidas que se foram, os signos do sofrimento e da exploração em que milhares se viram mergulhados.

O tom de denúncia que o trecho apresenta quando fala da coleira, associando-a a um crime, e a clara simpatia que nutre em relação a esse objeto revela bem a proximidade da visão de mundo do autor àquela implícita nas teses de Benjamin. Segundo o filósofo alemão, é necessário "escovar a história a contrapelo" (BENJAMIN, 2004, p. 225) para revelar o seu "outro lado"; e é exatamente isso o que Saramago parece fazer nesse trecho, buscando numa cidade cheia de referências ao poder institucional, erguido, convém lembrar, sobre séculos e 
séculos de violência, justamente uma prova de que outras histórias de Lisboa podem ser contadas - especialmente aquelas que se ligam às populações escravizadas ou exploradas pela divisão da sociedade em classes que funda Portugal e todas as demais nações do Ocidente.

O questionamento que Saramago propõe ao leitor e que dá título a este artigo, entre várias outras possibilidades, abre um espaço para a discussão do próprio conceito de viagem. Para ele, "viajar é descobrir, o resto é simples encontrar" (SARAMAGO, p. 352). E a viagem que o narrador realiza dentro de seu próprio país configura-se como uma viagem no interior de si mesmo, uma viagem infinita, uma forma de demonstrar que

A viagem não acaba nunca. Só os viajantes acabam. E mesmo estes podem prolongar-se em memória, em lembrança, em narrativa. Quando o viajante se sentou na areia da praia e disse: "Não há mais que ver", sabia que não era assim. O fim duma viagem é apenas o começo doutra. (SARAMAGO, p. 475-6)

Denúncia, crítica, descoberta e redescoberta. Pergunta-se, então, como o fez Saramago: Que viajar é este? É um viajar que traz em si todos estes elementos, uma viagem que percorre não apenas um país, mas também sua história; um trajeto que constrói e reconstrói a memória e que fundamenta a identidade de um povo. Um olhar que descreve o velho como se fosse novo, que critica ao mesmo tempo em que enaltece, e que, nessa enorme profusão de sentimentos, de imagens e de relatos, termina por carregar consigo um leitor que, de certo modo, passa a conhecer Portugal pelo olhar do viajante.

\section{Referências bibliográficas}

ACHUGAR, Hugo. Planetas sem boca: escritos efêmeros sobre arte, cultura e literatura. Trad. Lyslei Nascimento. Belo Horizonte: Ed. UFMG, 2006. 
BENJAMIN, Walter. Magia e técnica, arte e politica: ensaios sobre literatura e história da cultura. Trad. Sérgio Paulo Rouanet. 7.ed. São Paulo: Brasiliense, 1996.

CRISTÓVÃO, Fernando. "Para uma teoria da literatura de viagens." In: CRISTÓVÃO, Fernando (Org.) Condicionantes culturais da literatura de viagens: estudos e bibliografias. Coimbra: Almedina, 2002, p. 13-52.

LÉVI-STRAUSS, Claude. Tristes trópicos. Trad. Rosa Freire d'Aguiar. São Paulo: Companhia das Letras, 2007.

SARAMAGO, José. Viagem a Portugal. São Paulo: Companhia das Letras, 2007. 